Verein Psychosoziale Aspekte der Humangenetik e.V.

\title{
Einladung zur 19. Ordentlichen Mitgliederversammlung
}

Ort:

52062 Aachen, Kongresszentrum: Eurogress, Monheimsallee 48, Raum HASSELT

Zeit: Donnerstag, 02. April 2009, 12:00 - 13:00 Uhr

Liebe Kolleginnen, liebe Kollegen!

Hiermit möchte ich Sie/euch ganz herzlich zur 19. Ordentlichen Mitgliederversammlung des Vereins Psychosoziale Aspekte der Humangenetik VPAH e.V. am o2. April 2009 in Aachen einladen. Die Veranstaltung findet wie alljährlich im Rahmen der GfH-Jahrestagung statt.

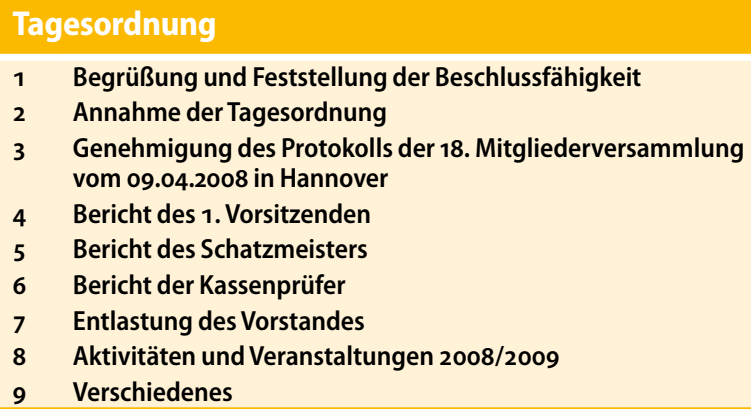

In der Hoffnung Sie/euch möglichst zahlreich in Aachen begrüßen zu können.
Mit freundlichen Grüßen Dipl. Psych. H. Joachim Schindelhauer-Deutscher 1. Vorsitzender 